\title{
PENINGKATAN KUALITAS BENANG DTY SINGLE 150D/48F PADA MESIN CONE WENDER MENGGUNAKAN METODE SIX SIGMA DAN FACTORIAL DESIGN DI PT. GEMILANG TEXINDOTAMA
}

\author{
Lithrone Laricha Salomon, Wilson Kosasih, dan Lilyana Jap \\ Program Studi Teknik Industri Universitas Tarumanagara \\ e-mail: Lilyanajap@yahoo.com
}

\begin{abstract}
ABSTRAK
PT. GMT merupakan perusahaan manufaktur dibidang tekstil yang menghasilkan berbagai macam ukuran dan jenis benang seperti benang single dan benang double (twist). Permasalahan yang dihadapi oleh perusahaan adalah banyak terjadinya kesalahan penggulungan benang di mesin cone wender sehingga benang tidak sesuai dengan standar. Untuk mengatasi permasalahan ini, dilakukan perancangan eksperimen dengan metode Factorial Design untuk menentukan settingan optimum mesin dan hasil interaksi setiap faktor yang berpengaruh. Dengan analisa FMEA dilakukan penelitian faktor seperti sambungan weight bound, genangan pelumas saat proses, benang putus saat diangkat, traverse length kurang panjang, dan berat doffing yang bervariasi. Dengan tiga tipe sisi mesin cone wender (12, 16, dan 32 sisi) terdapat tiga faktor utama yang mempengaruhi nilai untuk settingan mesin yaitu kecepatan putaran mesin (speed), traverse length, dan bandul bawah (weight bound). Pengujian settingan mesin yang dilakukan terdapat dua level, yakni level dengan keadaan perusahaan saat ini dan level yang diajukan. Berdasarkan hasil pengolahan data disimpulkan beberapa hal, yaitu: jenis cacat benang yang paling banyak dihasilkan adalah benang lingkar dan benang kotor., kapabilitas pada proses awal proses masih sangat rendah dan perlu ditingkat, faktor yang berpengaruh dalam settingan optimum mesin cone wender adalah Speed (400 RPM) dan Weight bound (40 gr). Dari hasil analisa simulasi penerapan didapatkan Grade A mengalami peningkatan 95.45317 \% menjadi $95.58280985 \%$. Berarti peningkatan naik sebesar $0.129 \%$ (per minggu).
\end{abstract}

Kata kunci: FMEA, Anova, Design factor, Optimasi

\begin{abstract}
PT. GMT is a field of textile manufacturing company that produces a variety of sizes and types of yarn as yarn single and double yarn (twist). The problem faced by the company is a lot of error in the thread rolling machine Wender cone so that the thread does not conform to the standard. To overcome this problem, the design of experiments carried out by the method of factorial design to determine the optimum machine settings and the results of each of the factors that influence the interaction. FMEA analysis conducted research with factors such as connection weight bound, while the pool of lubricants, thread break when lifted, less long traverse length, and weight varied doffing. With three types of cone machine side Wender (12, 16, and 32 sides) there are three main factors that affect the value of the setting of the machine that the engine rotation speed (speed), traverse length, and the lower pendulum (weight bound). Testing machine settings made there are two levels, namely level with the state of the company's current and proposed levels. Based on the results of data processing was concluded a few things: the type of yarn defects are the most widely produced yarn and thread ring dirty., Capability at the beginning of the process is still very low and needs to be level, factors that affect the optimum settings Wender cone machine is Speed (400 RPM) and Weight bound (40 gr). From the analysis results obtained Grade A simulation application increased $95.45317 \%$ to $95.58280985 \%$. Means an increase rose by $0.129 \%$ (per week).
\end{abstract}

Keyword: FMEA, Anova, Design factor, Optimization

\section{PENDAHULUAN}

Department cone wender merupakan department pada PT. GMT dimana proses penggulungan benang berlangsung. Menurut hasil wawancara, hasil defect pada produk paling banyak ditemukan pada mesin cone wender yang nantinya akan dilakukan rework 
(penggulungan ulang) benang dengan tujuan untuk meningkatkan mutu kualitas serta performansi benang.

Penelitian ini menganalisa masalah-masalah yang terjadi di lapangan sehingga dapat diketahui masalah-masalah penyebab defect pada proses penggulungan benang (cone wender) dan mencari pengaturan yang optimum untuk mesin cone wender yang diharapkan dapat mengurangi defect. Oleh karena itu pada tahap selanjutnya masalah-masalah tersebut dianalisis secara terperinci dan sistematis dengan menggunakan metode six Sigma yakni DMAIC dan menggunakan peta control atribut dalam melakukan perhitungan cacat yang terjadi serta dilakukan percobaan dan perhitungan serta analisa untuk mencari settingan optimum mesin dengan menggunakan metode Design of Experiment (DOE).

Tujuan dari penelitian yang dilakukan di mesin cone wender adalah: mengetahui faktorfaktor yang berpengaruh secara signifikan terhadap setting mesin cone wender, mencari pengaturan optimum mesin cone wender supaya dapat mengurangi jumlah produk cacat, dan menganalisa hasil dari perhitungan dengan menggunakan metode DOE, sudah layak atau belum untuk diterapkan di PT. GMT

\section{TINJAUAN PUSTAKA}

Kualitas suatu produk adalah (minimasi) kerugian yang diberikan oleh produk kepada masyarakan sejak produk tersebut dikirimkan [1]. Kualitas ditentukan oleh pelanggan, dimana pelanggan ingin produk dan jasa memenuhi kebutuhan dan harapannya ada suatu harga tertentu yang menunjukkan nilai produk tersebut [2].

Untuk mencapai hasil kualitas yang baik, tentunya diperlukan pengendalian kualitas. Dapat dilakukan dengan 2 cara, yakni on-line quality control dan off-line quality control.On-line quality control adalah kegiatan pengendalian kualitas yang dilakukan selama proses produksi berlangsung dengan menggunakan statistical process control $(S P C)$. Sifat yang dimiliki oleh on-line qulity control adalah yindakan yang reaktif, atau tindekan setelah kegiatan produksi berjalan. Artinnya jika terdapat hasil produksi yang tidak dapat memenuhi spesifikasi yang diperlukan, maka tindakan akan langsung dilakukan kepada proses produksi atau dengan kata lain dilakukan perbaikan proses.

Tujuan pengendalian kualitas menurut pandangan 2 ahli pengendalian kualitas, A.V.Feigenbum dan Drs. Sofyan Assauri, yakni:

Menurut A.V.Feigenbum tujuan pengendalian kualitas ialah [3]:

1. Pencapaian kebijaksanaan dan target perusahaan secara efisien

2. Perbaikan hubungan antara manusia dan peralatan

3. Peningkatan moral karyawan

4. Pengembangan kemampuan tenaga kerja

Menurut Drs. Sofyan Assauri tujuan pengendalian kualitas ialah [4]:

1. Agar barang hasil produksi dapat mencapai standar mutu yang telah ditetapkan

2. Mengusahakan agar biaya inspeksi dapat menjadi sekecil mungkin

3. Mengusahakan agar biaya desain dari produk dan proses dengan menggunakan mutu produksi tertentu dapat menjadi serendah mungkin

4. Mengusahakan agar biaya produksi dapat menjadi serendah mungkin.

Six sigma adalah suatu visi peningkatan kualitas menuju target 3,4 kegagalan persejuta kesempatan (Defect Per Million Opportunity-DPMO) untuk setiap transaksi produk (barang atau jasa). Six sigma merupakan sebuah terobosan baru dalam bidang manajemen kualitas berupa suatu metode atau teknik pengendalian dan peningkatan kualitas dramatik menuju tingkat kegagalan 0 (zero defect). Six sigma merupakan pendekatan menyeluruh untuk menyelesaikan masalah dan peningkatan proses melalui fase DMAIC (Define, Measure, Analyse, Improve, Control), sedangkan DMAIC merupakan jantung 
analisis six sigma yang menjamin voice of customer berjalan dalam keseluruhan proses sehingga produk yang dihasilkan memuaskan keinginan pelanggan.

Factorial design digunakan untuk dampak simultan lebih dari satu variabel bebas. Kombinasi simultan merupakan manipulasi. Masing-masing kombinasi simultan diamati dan diperbandingkan.

Berikut rumus yang digunakan dalam perhitungan yang dapat dilihat pada gambar dibawah ini beserta dengan langkah metodologi penelitian.

Tabel 1 Rumus Design factor

\begin{tabular}{lcclc}
\hline $\begin{array}{l}\text { Source of } \\
\text { Variation }\end{array}$ & $\begin{array}{c}\text { Sum of } \\
\text { Squares }\end{array}$ & $\begin{array}{c}\text { Degrees of } \\
\text { Freedom }\end{array}$ & \multicolumn{1}{c}{ Mean Square } & $F_{0}$ \\
\hline$A$ treatments & $S S_{A}$ & $a-1$ & $M S_{A}=\frac{S S_{A}}{a-1}$ & $F_{0}=\frac{M S_{A}}{M S_{E}}$ \\
$B$ treatments & $S S_{B}$ & $b-1$ & $M S_{B}=\frac{S S_{B}}{b-1}$ & $F_{0}=\frac{M S_{B}}{M S_{E}}$ \\
Interaction & $S S_{A B}$ & $(a-1)(b-1)$ & $M S_{A B}=\frac{S S_{A B}}{(a-1)(b-1)}$ & $F_{0}=\frac{M S_{A B}}{M S_{E}}$ \\
Error & $S S_{E}$ & $a b(n-1)$ & $M S_{E}=\frac{S S_{E}}{a b(n-1)}$ & \\
Total & $S S_{T}$ & $a b n-1$ & & \\
\hline
\end{tabular}

Dengan:

$$
\begin{aligned}
& S S_{T}=\sum_{i=1}^{a} \sum_{j=1}^{b} \sum_{k=1}^{\mathrm{n}} \mathrm{y}_{\mathrm{ijk}}-\frac{y_{m}^{2}}{a b n} \\
& S S_{A}=\frac{1}{b n} \sum_{i=1}^{a} y_{i_{\mathrm{s}}}^{2}-\frac{y_{\mathrm{s}}^{2}}{a b n} \\
& S S_{B}=\frac{1}{a n} \sum_{j=1}^{b} y_{. j_{*}}^{2}-\frac{y_{s}^{2}}{a b n} \\
& S S_{\text {Subtotals }}=\frac{1}{n} \sum_{i=1}^{a} \sum_{j=1}^{b} y_{i j .}^{2}-\frac{y_{\text {. }}^{2}}{a b n} \\
& S S_{A B}=S S_{\text {Subtotals }}-S S_{A}-S S_{B} \\
& S S_{E}=S S_{T}-S S_{\text {Subtotals }}
\end{aligned}
$$

Berikut rumus yang digunakan dalam perhitungan yang dapat dilihat pada gambar dibawah ini beserta dengan langkah metodologi penelitian.

Tabel 1 Rumus Design factor

\begin{tabular}{lcclc}
\hline $\begin{array}{l}\text { Source of } \\
\text { Variation }\end{array}$ & $\begin{array}{c}\text { Sum of } \\
\text { Squares }\end{array}$ & $\begin{array}{c}\text { Degrees of } \\
\text { Freedom }\end{array}$ & \multicolumn{1}{c}{ Mean Square } & $F_{0}$ \\
\hline$A$ treatments & $S S_{A}$ & $a-1$ & $M S_{A}=\frac{S S_{A}}{a-1}$ & $F_{0}=\frac{M S_{A}}{M S_{E}}$ \\
$B$ treatments & $S S_{B}$ & $b-1$ & $M S_{B}=\frac{S S_{B}}{b-1}$ & $F_{0}=\frac{M S_{B}}{M S_{E}}$ \\
Interaction & $S S_{A B}$ & $(a-1)(b-1)$ & $M S_{A B}=\frac{S S_{A B}}{(a-1)(b-1)}$ & $F_{0}=\frac{M S_{A B}}{M S_{E}}$ \\
Error & $S S_{E}$ & $a b(n-1)$ & $M S_{E}=\frac{S S_{E}}{a b(n-1)}$ & \\
Total & $S S_{T}$ & $a b n-1$ & & \\
\hline
\end{tabular}


Dengan:

$$
\begin{aligned}
& S S_{T}=\sum_{i=1}^{a} \sum_{j=1}^{b} \sum_{k=1}^{\mathrm{n}} \mathrm{y}_{\mathrm{ijk}}-\frac{y_{m}^{2}}{a b n} \\
& S S_{A}=\frac{1}{b n} \sum_{i=1}^{a} y_{i s}^{2}-\frac{y_{m}^{2}}{a b n} \\
& S S_{B}=\frac{1}{a n} \sum_{j=1}^{b} y_{. j_{.}}^{2}-\frac{y_{m}^{2}}{a b n} \\
& S S_{\text {Subtotals }}=\frac{1}{n} \sum_{i=1}^{a} \sum_{j=1}^{b} y_{i j .}^{2}-\frac{y_{m}^{2}}{a b n} \\
& S S_{A B}=S S_{\text {Subtotals }}-S S_{A}-S S_{B} \\
& S S_{E}=S S_{T}-S S_{\text {Subtotals }}
\end{aligned}
$$

\section{METODOLOGI PENELITIAN}

Tahap pengumpulan data ini dilakukan dengan melakukan penelitian perancangan eksperimen pada mesin cone wender dengan 3 macam sisi $(12,16$, dan 32 sisi) dengan 3 faktor yang diuji, yakni speed, traverse length, dan weight bound, serta level yang diajukan berjumlah 2. Level 1 untuk keadaan perusahaan saat ini (Speed $300 \mathrm{rpm}$, traverse length $15 \mathrm{ml}$, dan weight bound $30 \mathrm{gr}$ ) sedangkan level 2 merupakan level yang diajukan atas permintaan perusahaan (Speed $300 \mathrm{rpm}$, traverse length $15 \mathrm{ml}$, dan weight bound $30 \mathrm{gr}$ ). Hasil dari perancangan ini ditunjukan untuk mengetahui faktor apa saja yang berpengaruh dengan melakukan pengujian hipotesa serta bagaimana hubungan korelasi untuk faktor yang berpengaruh dan melakukan perhitungan dengan menggunakan metode Design factorial.

Dalam pengolahan data yang dilakukan, menggunakan prinsip DMAIC, yang antara lain berupa define, measure, analyze, improve dan control. Setiap tahap DMAIC menggunakan metode yang sesuai dengan data untuk menguji sebuah perancangan eksperimen yang dilakukan. Berikut ini merupakan langkah-langkah pengolahan data yang dilakukan, yaitu:

1. Melakukan uji kenormalan data

2. Membuat hipotesa untuk pengujian setiap faktor

3. Melakukan analisa terhadap efek utama dan efek interaksi dari faktor yang diteliti

4. Menghitung hubungan korelasi faktor yang berpengaruh

5. Menentukan nilai optimal untuk tiap faktor yang diuji untuk menghasilkan nilai settingan optimal mesin yang terbaik.

Diagram alir dari metodologi penelitian seperti yang ditunjukkan pada Gambar 1. 


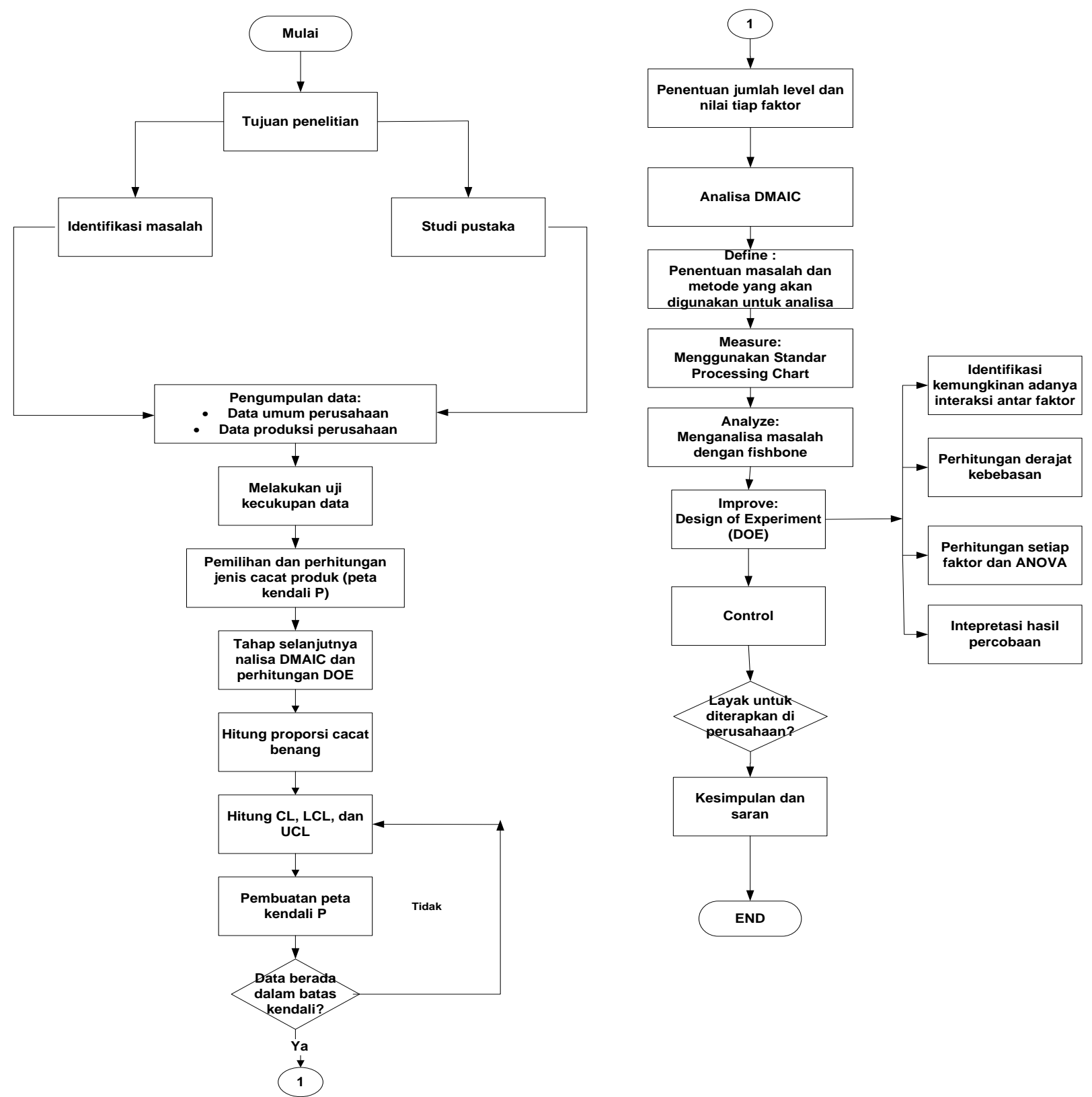

Gambar 1. Metodologi Penelitian

\section{Define}

\section{HASIL DAN PEMBAHASAN}

Define atau pengidentifikasian tentang jumlah cacat perhari serta menggunakan diagram SIPOC untuk menentukan yang digunakan untuk mengetahui jalannya proses kerja yang ada di perusahaan mulai dari awal hingga akhir dari produk tersebut.

\section{Diagram SIPOC}

Diagram SIPOC merupakan alat yang digunakan dalam peningkatan proses, sehingga dapat dilakukan perbaikan terhadap masalah yang ada di dalam proses. Diagram SIPOC menyajikan tampilan singkat dari aliran kerja. Berikut ini merupakan diagram SIPOC proses produksi benang single pada PT. GMT dapat dilihat pada Gambar 2 Diagram SIPOC:

Supplier : Jinzhou City Dingfu Textiles Co., Ltd, Quanzhou 
Xinxinglilai Fibre \& Textile Co., Ltd., Wenlong Group Shanghai

Trading Co., Ltd.

Inputs $\quad$ : Bahan baku Parsial Oriented Yann (POY) dan PE.

Process : Texturizing, dyeing, cone wender, dan quality control \& packaging

Outputs : Benang single 150D - 48 F

Customer : PT. Ramagloria Sakti Tekstil Industri, PT Sampangan Duta Panca Sakti

Tekstil, PT. Sentral Tekstil, PT Sandratex, dan PT. Sarana Mega Utama

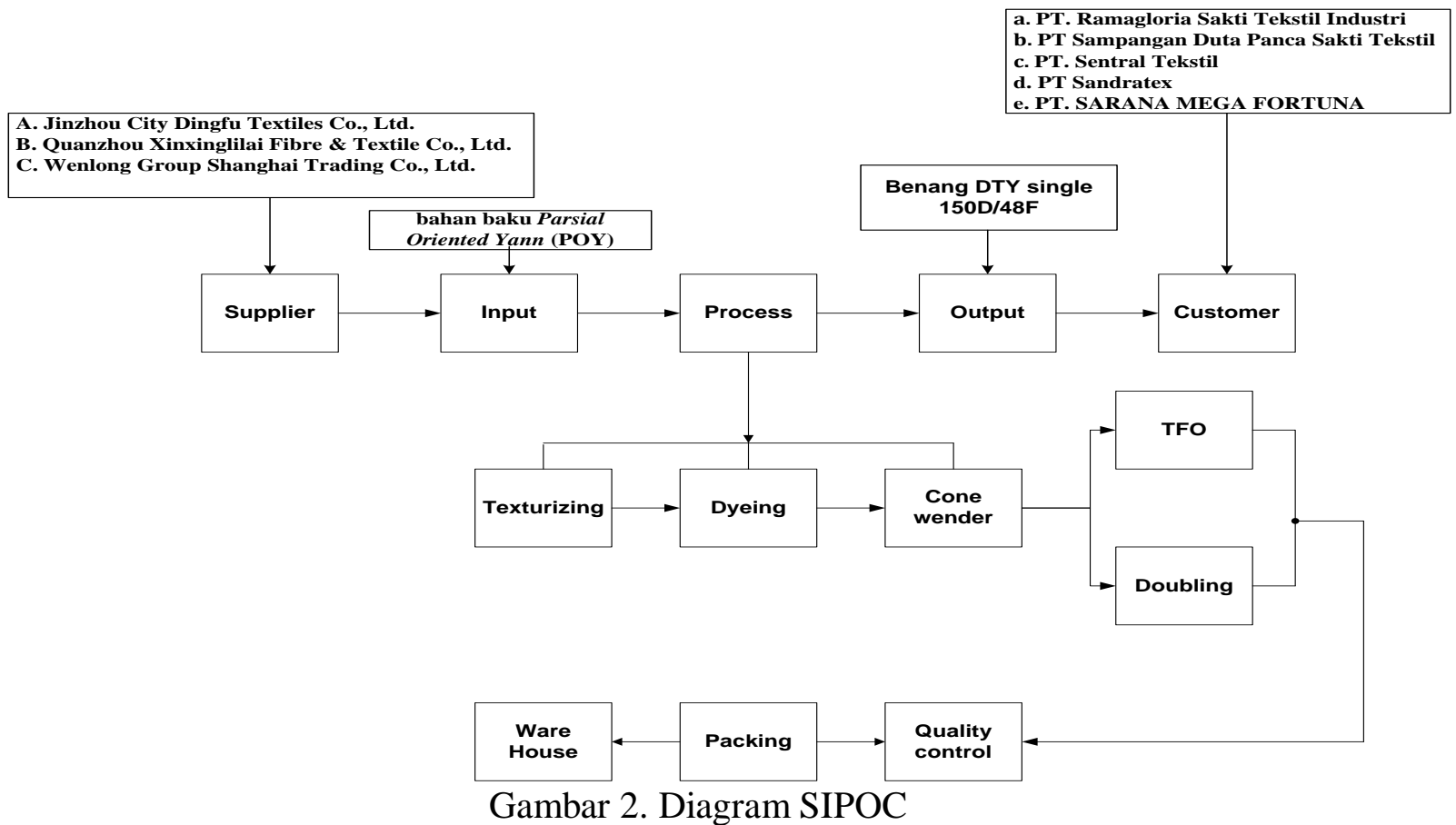

\section{DPMO}

Perhitungan DPMO dan level sigma bertujuan untuk mengukur kemampuan dan kapabilitas sigma pada saat ini. Dalam hal ini akan dihitung nilai DPMO pada bulan AprilMei 2013. Adapun nilai-nilai yang diperlukan untuk menghitung nilai DPMO yang perlu diketahui adalah Unit (U) yang menyatakan jumlah produk yang diperiksa dalam inspeksi, selama waktu pengamatan yaitu sebanyak 420,000 cones benang. Defect (D) yang menyatakan jumlah produk cacat yang terjadi selama waktu pengamatan yaitu sebanyak 3547 unit. Opportunity (OP) menyatakan karakteristik yang berpotensi menyebabkan cacat yaitu sebanyak enam (6), antara lain loop, bulu, kotor, lingkar, gelombang, dan sambungan sehingga nilai Opportunity $(\mathrm{OP})$ adalah 6.

Tabel 2 Perhitungan DPMO

\begin{tabular}{lc}
\hline \multicolumn{1}{c}{ Keterangan } & April-mei 2013 \\
\hline Unit & 420,000 cones \\
Oportunities & 6 \\
Defect & 3,547 \\
Defect per unit & 0.008445238 \\
Total Opportunities & $2,520,000.00$ \\
Defect Per opportunities & 0.00140754 \\
DPMO & 1407.5397 \\
Tingkat Sigma & 4.4375 Sigma \\
\hline
\end{tabular}




\section{Kapabilitas Proses}

Setelah proses berada dalam batas kendali dalam batas kendali, maka selanjutnya adalah menghitung kapabilitas proses. Dengan nilai $Z=1.24$ di dapatkan nilai Kapabilitas pada proses awal dengan nilai $\mathrm{Cp}=0.54$ dan nilai $\mathrm{CPk}=0.54$, setelah di lakukan iterasi nilai Cp dan nilai CPk meningkat menjadi 0.55. Dapat diartikan bahwa kemampuan proses masih sangat rendah dan perlu ditingkatkan.

\section{A. Measurement}

Tahap pengukuran atau measurement yang dilakukan adalah pengukuran terhadap tingkat cacat serta jenis cacat yang dihasilkan perusahaan. PT. GMT menghasilkan jenis cacat pada benang single yang digolongkan dalam cacat attribute dan pengolahan dengan PChart.

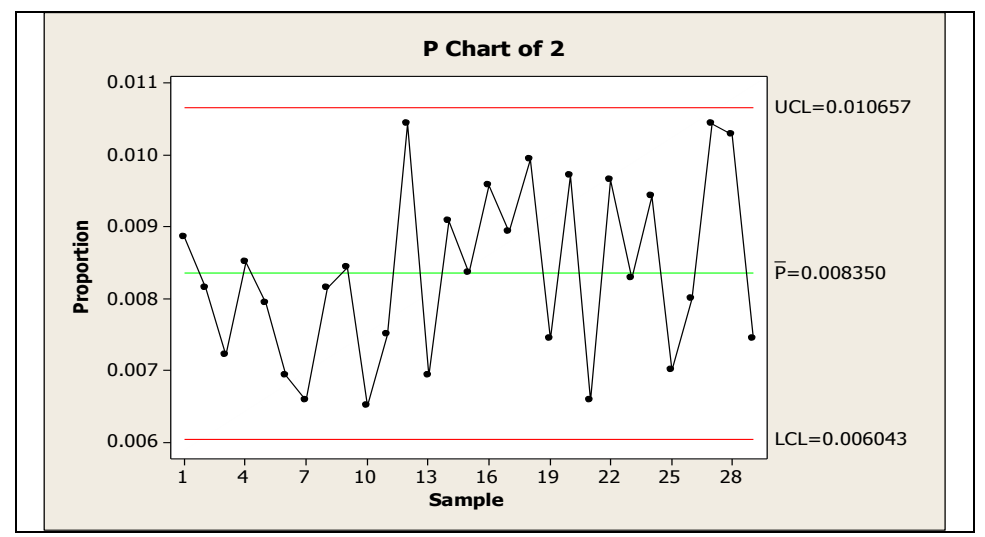

Gambar 3. Grafik P-Chart Data 2013

Tabel 4 Jumlah Cacat Pada Benang Single

\begin{tabular}{lcccccc}
\hline \multicolumn{1}{c}{ Jenis } & Bulan & $\begin{array}{c}\text { Jumlah Produksi } \\
\text { Produk }\end{array}$ & $\begin{array}{c}\text { Total } \\
\text { Produksi } \\
\text { (unit) }\end{array}$ & Cacat & Total & \% cacat \\
\hline Benang & April 2013 & 420,000 & 616,000 & 2332 & 3547 & 0.00575812 \\
Single & Mei 2013 & 196,000 & & 1215 & & \\
\hline
\end{tabular}

\section{B. Analyze}

\section{Fishbone Diagram}

Diagram yang digunakan untuk mengidentifikasikan segala penyebab kegagalan benang lingkar dari sudut pandang Man, Machine, Methode, dan Measurement. Tujuan dari fishbone untuk mencegah terjadinya kesalahan yang sama di masa mendatang.

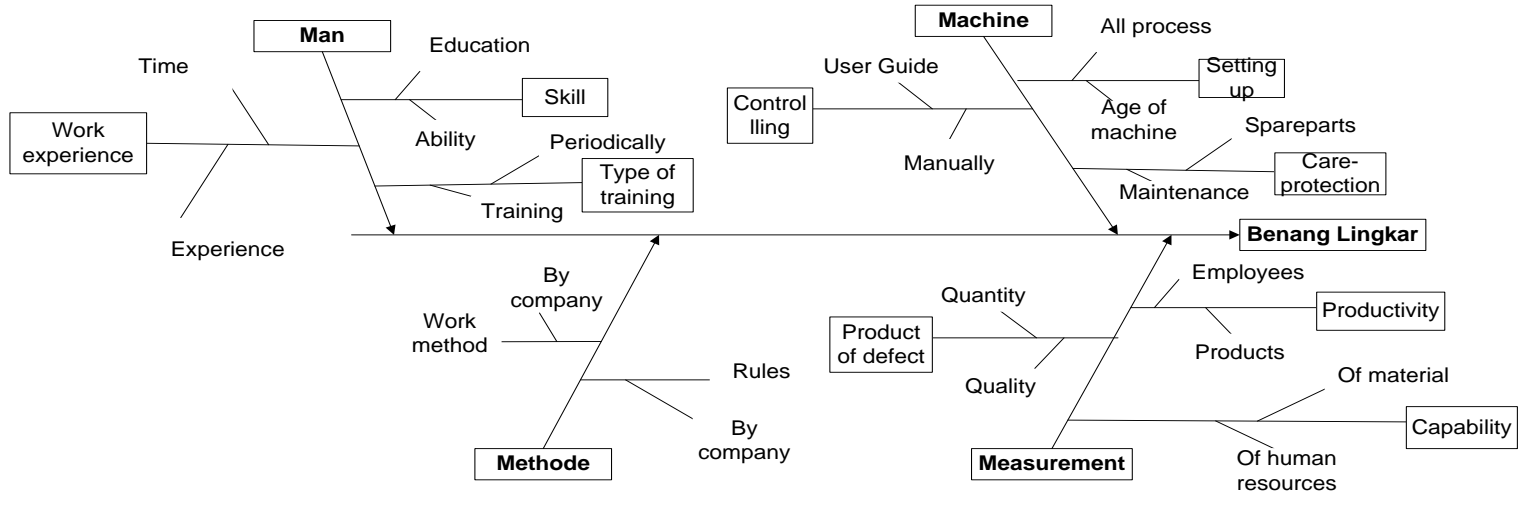

Gambar 4 Fishbone Untuk Benang Lingkar 


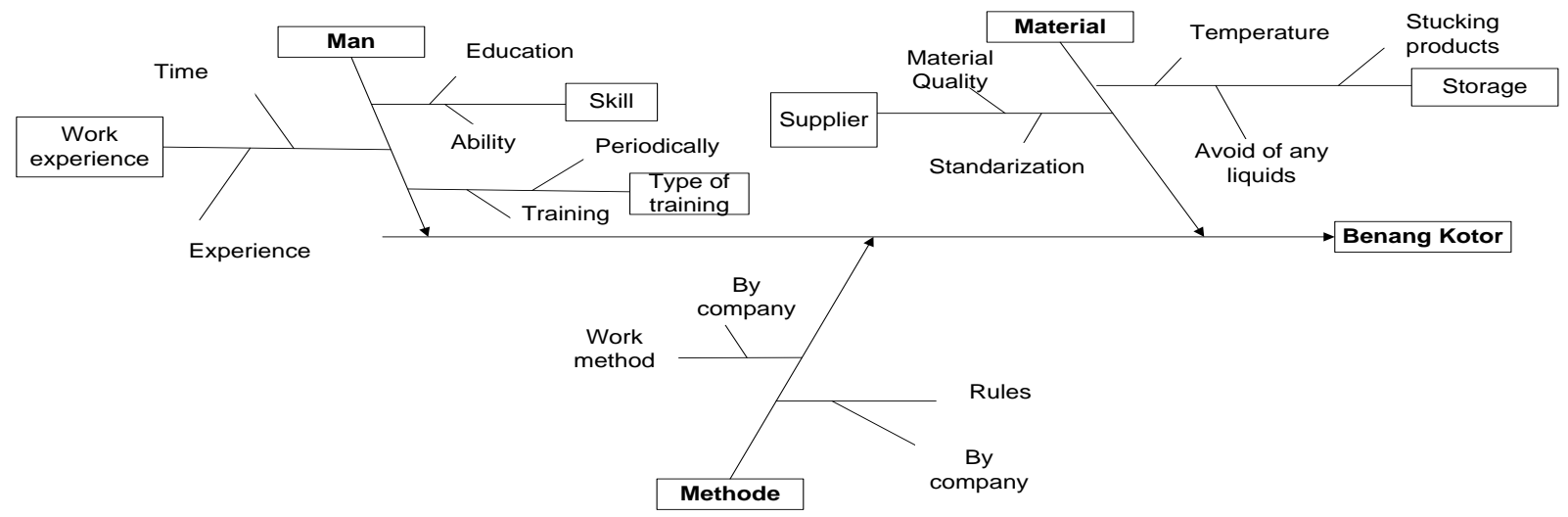

Gambar 5 Fishbone Untuk Benang Kotor

FMEA berguna untuk menganalisa serta memberi nilai rating bagi kegagalan yang sering terjadi untuk lebih ditangani lebih lanjut guna mengurangi defect di masa mendatang. Pada proses produksi benang di departemen mesin Cone wender setelah melewati tahap analisa dengan peta kendali $\mathrm{P}$, diagram pareto dan diagram sebab akibat, maka tahap selanjutnya yang dilakukan adalah mencari faktor yang paling berpengaruh terhadap jenis kegagalan dalam mesin Cone wender pada produksi benang jenis single dengan menggunakan metode FMEA atau FAILURE MODE AND EFFECT ANALYSIS, sehingga factor-faktor yang berpengaruh pada setiap proses dapat dikendalikan.

Tabel 5 Pemberian Rangking Prioritas

\begin{tabular}{|c|c|c|c|c|c|c|c|c|c|}
\hline No & $\begin{array}{l}\text { Fungsi } \\
\text { proses }\end{array}$ & $\begin{array}{c}\text { Efek } \\
\text { kegagalan }\end{array}$ & S & Penyebab kegagalan & $\mathrm{O}$ & $\begin{array}{c}\text { Kontrol yang } \\
\text { dilakukan }\end{array}$ & D & RPN & $\begin{array}{l}\text { Rang } \\
\text { king }\end{array}$ \\
\hline \multirow{7}{*}{1} & \multirow{7}{*}{$\begin{array}{c}\text { Cone } \\
\text { wender }\end{array}$} & $\begin{array}{l}\text { Loop dan } \\
\text { Bulu }\end{array}$ & \multirow{6}{*}{5} & $\begin{array}{c}\text { sambungan weight bound } \\
\text { cacat }\end{array}$ & 9 & $\begin{array}{c}\text { Pemeriksaan settingan } \\
\text { mesin }\end{array}$ & 8 & 360 & 1 \\
\hline & & Kotor & & $\begin{array}{c}\text { Genangan pelumas / oli saat } \\
\text { proses }\end{array}$ & 9 & Pemeriksaan workbench & 8 & 360 & 1 \\
\hline & & & & Berat doffing bervariasi & 7 & $\begin{array}{c}\text { Training karyawan kurang } \\
\text { cukup }\end{array}$ & 3 & 360 & 1 \\
\hline & & Lingkar & & $\begin{array}{c}\text { Benang putus lama tapi tidak } \\
\text { diangkat }\end{array}$ & 9 & $\begin{array}{c}\text { Training karyawan kurang } \\
\text { cukup }\end{array}$ & 3 & 135 & 2 \\
\hline & & \multirow{2}{*}{ Gelombang } & & $\begin{array}{c}\text { settingan weight bound tidak } \\
\text { rata }\end{array}$ & 9 & $\begin{array}{c}\text { Pemeriksaan settingan } \\
\text { mesin }\end{array}$ & 8 & 360 & 1 \\
\hline & & & & $\begin{array}{c}\text { Benang putus tidak langsung } \\
\text { diangkat }\end{array}$ & 7 & $\begin{array}{c}\text { Training karyawan kurang } \\
\text { cukup }\end{array}$ & 3 & 105 & 3 \\
\hline & & Sambungan & & $\begin{array}{l}\text { Traverse length kurang } \\
\text { panjang }\end{array}$ & 9 & $\begin{array}{l}\text { Pemeriksaan settingan } \\
\text { mesin }\end{array}$ & 8 & 360 & 1 \\
\hline
\end{tabular}

\section{Improve}

\section{Factorial Design}

Factorial Design yang dilakukan pada perancangan kali ini untuk menguji 3 faktor utama dengan replikasi sebanyak 7 kali untuk setiap level dan menggunakan 3 jenis mesin cone wender $(12,16$, dan 32 sisi) guna mencari settingan optimum pada mesin yang bertujuan dalam mengurangi cacat produk serta mencari nilai korelasi dari faktor yang disertai dengan pengujian hipotesa-hipotesa.

Berdasarkan hasil pengujian dengan software minitab untuk uji kenormalan data, dapat dilihat bahwa nilai P-Value yang didapatkan sebesar 0.404 dan lebih besar dari taraf signifikansi yang digunakan $(\alpha=0.1)$ sehingga dapat disimpulkan bahwa data memiliki distribusi normal. Pengujian untuk kesamaan variansi data juga menunjukkan bahwa nilai $\mathrm{P}$-Value yang diperoleh lebih besar dari taraf signifikansi yang digunakan $(\alpha=0.1)$ 
sehingga dapat disimpulkan bahwa standar deviasi dari setiap kumpulan data tersebut sama.

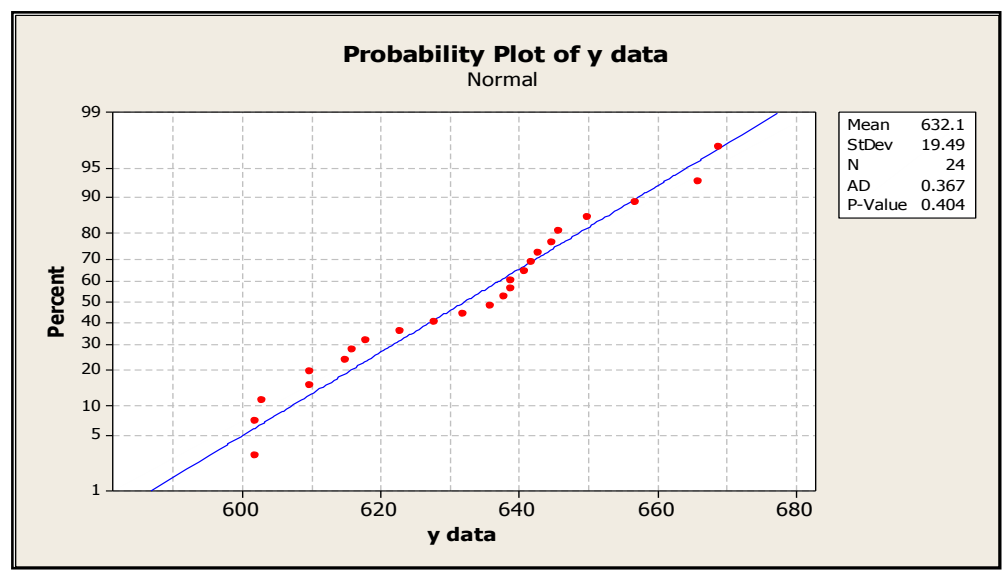

Gambar 6 Hasil pengujian distribusi normal dengan minitab

Improve / perbaikan yang dilakukan dalam penelitian ini menggunakan factorial desain untuk mencari settingan optimal. Berikut merupakan data hasil penelitian dengan melakukan pengujian di 3 tipe sisi mesin Cone wender $(12,16$, dan 32 sisi) dengan 3 faktor utama dan 2 level pengujian. Berikut merupakan tampilan hasil percobaan

Tabel 6 Data Perancangan Benang Single di Mesin Cone wender

\begin{tabular}{|c|c|c|c|c|c|c|c|c|c|c|}
\hline \multirow{3}{*}{ Speed (a) } & \multirow{4}{*}{$\begin{array}{c}\text { Lini } \\
\text { Mesin }\end{array}$} & \multicolumn{8}{|c|}{ TRAVERSE LENGTH (B) } & \multirow{4}{*}{ Yi..... } \\
\hline & & \multicolumn{4}{|c|}{15} & \multicolumn{4}{|c|}{16} & \\
\hline & & \multicolumn{4}{|c|}{ WEIGHT BOUND @ } & \multicolumn{4}{|c|}{ WEIGHT BOUND @ } & \\
\hline \multirow{10}{*}{300} & & \multicolumn{2}{|c|}{30} & \multicolumn{2}{|c|}{40} & \multicolumn{2}{|c|}{30} & \multicolumn{2}{|c|}{40} & \\
\hline & \multirow{3}{*}{12} & 616 & & 623 & \multirow{3}{*}{1878} & 618 & & 615 & \multirow{3}{*}{1857} & \multirow{3}{*}{7469} \\
\hline & & 610 & 1872 & 610 & & 602 & 1862 & 603 & & \\
\hline & & 646 & & 645 & & 642 & & 639 & & \\
\hline & \multirow{3}{*}{16} & 826 & & 833 & \multirow{3}{*}{2486} & 828 & & 827 & \multirow{3}{*}{2470} & \multirow{3}{*}{9901} \\
\hline & & 821 & 2475 & 826 & & 816 & 2470 & 819 & & \\
\hline & & 828 & & 827 & & 826 & & 824 & & \\
\hline & \multirow{3}{*}{32} & 1654 & & 1651 & \multirow{3}{*}{4844} & 1641 & & 1644 & \multirow{3}{*}{4821} & \multirow{3}{*}{19404} \\
\hline & & 1632 & 4929 & 1541 & & 1526 & 4810 & 1533 & & \\
\hline & & 1643 & & 1652 & & 1643 & & 1644 & & \\
\hline & & \multicolumn{2}{|c|}{9276} & \multicolumn{2}{|c|}{9208} & & & \multicolumn{2}{|c|}{9148} & \\
\hline \multirow{11}{*}{400} & \multirow{3}{*}{12} & 650 & & 643 & \multirow{3}{*}{1947} & 639 & & 636 & & \\
\hline & & 641 & 1960 & 638 & & 628 & 1927 & 632 & 1925 & 7759 \\
\hline & & 669 & & 666 & & 660 & & 657 & & \\
\hline & & 848 & & 847 & & 846 & & 847 & & \\
\hline & 16 & 844 & 2549 & 841 & 2543 & 835 & 2527 & 835 & 2528 & 10147 \\
\hline & & 857 & & 855 & & 846 & & 846 & & \\
\hline & & 1673 & & 1672 & & 1664 & & 1666 & & \\
\hline & 32 & 1560 & 4905 & 1556 & 4897 & 1546 & 4865 & 1548 & 4870 & 19537 \\
\hline & & 1672 & & 1669 & & 1655 & & 1656 & & \\
\hline & & & & & & & & & & Y....... \\
\hline & $\mathrm{BXC}$ & & & & & & & & & 74217 \\
\hline
\end{tabular}


Tabel 7 Data perancangan eksperimen

\begin{tabular}{lcccccc}
\hline \multirow{2}{*}{$\mathrm{A}$} & \multicolumn{2}{c}{$\mathrm{B}$} & \multirow{2}{*}{$\mathrm{A}$} & \multicolumn{2}{c}{$\mathrm{C}$} \\
\cline { 2 - 3 } \cline { 6 - 7 } & 15 & 16 & & 30 & 400 \\
\hline 300 & 18484 & 18290 & & 300 & 18418 & 18356 \\
400 & 18801 & 18642 & & 400 & 18733 & 18710 \\
\hline
\end{tabular}

Penentuan hipotesa untuk tiap faktor yang akan dianalisa adalah sebagai berikut :

$\mathrm{H}_{01}=$ Faktor speed tidak berpengaruh secara signifikan terhadap hasil eksperimen

$\mathrm{H}_{02}=$ Faktor traverse length tidak berpengaruh secara signifikan terhadap hasil eksperimen

$\mathrm{H}_{03}=$ Faktor weight bound tidak berpengaruh secara signifikan terhadap hasil eksperimen

$\mathrm{H}_{04}=$ Interaksi factor speed, traverse length, dan weight bound tidak berpengaruh secara signifikan terhadap hasil eksperimen

$\mathrm{H}_{05}=$ Interaksi speed dan traverse length tidak berpengaruh secara signifikan terhadap hasil eksperimen

$\mathrm{H}_{06}=$ interaksi traverse length dan weight bound tidak berpengaruh secara signifikan terhadap hasil eksperimen

$\mathrm{H}_{07}=$ Interaksi speed dan weight bound tidak berpengaruh secara signifikan terhadap hasil eksperimen

$\mathrm{H}_{11}=$ Faktor speed berpengaruh secara signifikan terhadap hasil eksperimen

$\mathrm{H}_{12}=$ Faktor traverse length berpengaruh secara signifikan terhadap hasil eksperimen

$\mathrm{H}_{13}=$ Faktor weight bound berpengaruh secara signifikan terhadap hasil eksperimen

$\mathrm{H}_{14}=$ Interaksi factor speed, traverse length, dan weight bound berpengaruh secara signifikan terhadap hasil eksperimen

$\mathrm{H}_{15}=$ Interaksi speed dan traverse length berpengaruh secara signifikan terhadap hasil eksperimen

$\mathrm{H}_{16}=$ Interaksi traverse length dan weight bound berpengaruh secara signifikan terhadap hasil eksperimen

$\mathrm{H}_{17}=$ Interaksi speed dan weight bound berpengaruh secara signifikan terhadap hasil eksperimen

Setelah membuat hipotesa, data yang diperoleh kemudian diuji dengan menggunakan software minitab untuk menentukan kebenaran dari masing-masing hipotesa yang dibuat. Hasil pengolahan data adalah sebagai berikut:

Tabel 8 Hasil Perhitungan dengan Menggunakan Software Minitab

\begin{tabular}{lrrrrrr}
\hline \multicolumn{7}{c}{ Analysis of Variance for y } \\
\hline Source & DF & \multicolumn{1}{c}{ Seq SS } & \multicolumn{1}{c}{ Adj SS } & Adj MS & \multicolumn{1}{c}{ F } & \multicolumn{1}{c}{ P } \\
Blocks & 1 & 1731 & 1731 & 1731 & 0.01 & 0.922 \\
Main Effects & 3 & 993853 & 993853 & 993853 & 1.87 & 0.144 \\
$\quad$ Speed & 1 & 366511 & 366511 & 366511 & 2.07 & 0.155 \\
Tl & 1 & 101175 & 101175 & 101175 & 0.57 & 0.453 \\
Wb & 1 & 526167 & 526167 & 526167 & 2.97 & 0.09 \\
2-way Interactions & 13 & 832482 & 832482 & 832482 & 1.57 & 0.206 \\
$\quad$ Speed * tl & 1 & 9045 & 9045 & 9045 & 0.05 & 0.822 \\
Speed * wb & 1 & 806662 & 806662 & 806662 & 4.55 & 0.037 \\
$\quad$ tl wb & 1 & 16775 & 16775 & 16775 & 0.09 & 0.759 \\
Residual Error & 64 & 11337665 & 11337665 & 11337665 & & \\
$\quad$ Pure Error & 64 & 11337665 & 11337665 & 11337665 & & \\
\hline Total & 71 & 13165730 & & & & \\
\hline
\end{tabular}


Berdasarkan hasil perhitungan maka dapat dibuat persamaan sebagai berikut:

Settingan optimal $=1030.79+71.35 \mathrm{a}-85.49 \mathrm{~b}+105.85 \mathrm{ab}$

Dengan : $\mathrm{a}=$ speed

$\mathrm{b}=$ weight bound

\section{Analisa Control}

Dalam melakukan analisa terhadap control yang akan dilakukan, akan dibagi menjadi dua bagian besar dimana membandingkan data keadaan sebelum dengan sesudah serta dilakukan permisalan dengan asumsi bahwa produksi perbulan konstan, waktu doffing yang dibutuhkan sama perharinya, efisiensi mesin yang digunakan $85 \%$, dan waktu dalam permisalan digunakan selama 4 minggu (1 bulan)

A. Target yang diutamakan dalam penerapan kedepannya unytuk meningkatkan Grade A dan serta penambahan jumlah hasil produksi. Dari Tabel 7 perancangan eksperimen yang didapatkan diatas, dapat diketahui bahwa peningkatan Grade A terjadi dari $95.45 \%$ menjadi $95.58 \%$. Berarti peningkatan naik sebesar $0.129 \%$. Hal ini berarti bila diasumsikan dalam 1 hari PT. GMT dengan keadaan saat ini dapat menghasilkan 14000 pcs. Bila terjani kenaikan sebesar $0.129 \%$., maka hal ini menandakan jumlah produksi akan meningkat sebessar 14020 pcs perhari nya. Otomatis keuntungan yang didapat juga akan lebih banyak dihasilkan

B. Rework yang terjadi dari keadaan saat ini dengan usulan settingan yang baru meningkat dari $0.75 \%$ menjadi $0.77 \%$. berarti terjadi peningkatan sebesar $0.02 \%$. dengan kata lain produk yang harus di rework dari awalnya biasa perhari ada 9 pcs, meningkat jadi sekitar 10 pcs.

\section{KESIMPULAN}

Berdasarkan hasil pengolahan data dan analisa yang telah dilakukan, dapat disimpulkan beberapa hal, yaitu: jenis cacat benang yang paling banyak dihasilkan adalah benang lingkar dan benang kotor, kapabilitas pada proses awal dengan nilai $\mathrm{Cp}=0.54$ dan nilai $\mathrm{CPk}=0.54$. Setelah di lakukan iterasi nilai $\mathrm{Cp}$ dan nilai $\mathrm{CPk}$ meningkat menjadi 0.55 dapat diartikan bahwa kemampuan proses masih sangat rendah dan perlu ditingkatkan. Faktor berpengaruh dalam settingan optimum mesin cone wender adalah Speed (400 RPM) dan Weight bound (40 gr). Hubungan korelasi yang didapat dari perancangan eksperimen, Settingan optimal $=1030.79+71.35 a-85.49 b+105.85 a b$. Dari hasil analisa simulasi penerapan didapatkan Grade A mengalami peningkatan $95.45 \%$ menjadi $95.58 \%$. Berarti peningkatan naik sebesar $0.129 \%$ (per minggu).

\section{DAFTAR PUSTAKA}

[1].Ariani, Dorothea Wahyu, 1993, Manajemen Kualitas. Jakarta: Ghalia Indonesia.

[2].Bagchi, Tapan P., 1993, Taguchi Methods Explained: Practical Steps to Robust Desain. India: Prentice Hall, 1993

[3].Belavendram, Nicolo, 1995, Quality By Design. India: Prentice Hall.1995.

[4].Feigenbaum, A.V. 1992. Kendali Mutu Terpadu. Edisi Ketiga. Erlangga. Jakarta.

[5].Assauri, Sofjan, 2004, Manajemen Produksi dan Operasi Edisi Revisi, Lembaga Penerbit FE-UI, Jakarta, 2004.

[6].Pande, Peter S, Robert P. Newman, Roland R. Cavanagh (2002), “The Six Sigma Way: bagaimana GE, Motorola dan PerusahaanTerkenal Lainnya Mengasah Kinerja Mereka", Yogyakarta, Andi. 